\title{
Fellutamide B Synthetic Path Intermediates with in Vitro Neuroactive Function Shows Mood-Elevating Effect in Stress- Induced Zebrafish Model
}

\author{
R. Gajendra Reddy, ${ }^{\dagger, \|, \perp, \#}$ Soma Shekar Dachavaram, ${ }^{\ddagger}, \perp, \nabla$ B. Raghunath Reddy, ${ }^{\dagger, \|}$ \\ Kondbarao Balasaheb Kalyankar, ${ }^{\ddagger, \|}$ Wenson D. Rajan, ${ }^{\S, \bigcirc}$ Scherazad Kootar, ${ }^{\S,}$ Arvind Kumar, ${ }^{\S, \|}$ \\ Saibal Das, ${ }^{*},+\| l$ and Sumana Chakravarty ${ }^{*},+\| \odot$ \\ ${ }^{\dagger}$ Chemical Biology and ${ }^{\ddagger}$ Natural Products Chemistry, CSIR-Indian Institute of Chemical Technology, Tarnaka, Uppal Road, \\ Hyderabad 500007, India \\ ${ }^{\S}$ CSIR-Centre for Cellular and Molecular Biology, Habsiguda, Uppal Road, Hyderabad 500007, India \\ "Academy of Scientific and Innovative Research (AcSIR), Chennai 600113, India
}

Supporting Information

\begin{abstract}
Fellutamide B is reported to have cytotoxic and proteasome inhibitory activity. Interestingly, fellutamide B and its simplified analogues have also been observed for the neurotrophic activity by stimulating the synthesis and secretion of neurotrophins. Owing to the interesting structural and potent neurotrophic role of fellutamide B (a lipopeptide aldehyde), we have assessed the synthetic path intermediates (compounds A-D) of fellutamide B for their neuroactive potential (in vitro and in vivo). We have observed few compounds (comp \#A-D) to have potential neurite outgrowth activity in Neuro2a cells with no observable negative effect on the cell viability. In addition, most compounds

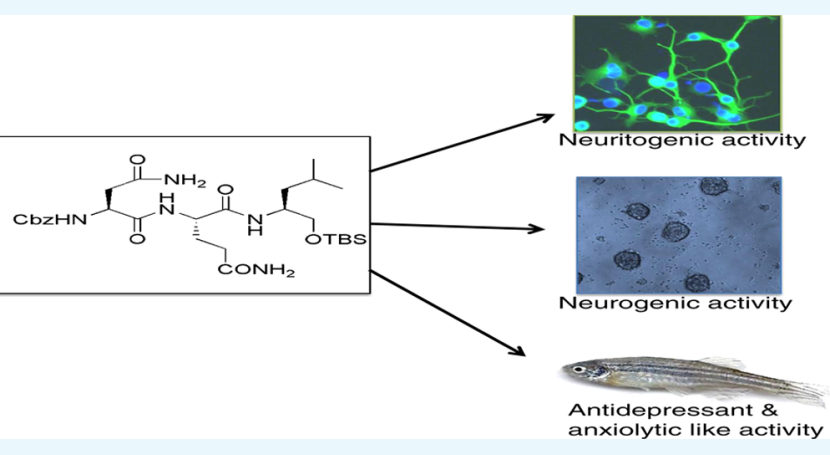
(comp \#A, C, and D) have shown neurogenic activity ex vivo in hippocampal neurosphere culture, with increased acetyl H3 and acetyl H4 induction ability (comp \#C). Furthermore, the intermediate product comp \#C has shown anxiolytic and antidepressant-like activity in novel tank test and social interaction test, in the chronic unpredictable stress model of zebrafish mood disorder, inducing BDNF gene expression in the telencephalon region of the fish brain. Our results thus demonstrate that the fellutamide B synthetic path intermediates have potential neurotrophic, neurogenic, and mood-elevating effects and thus good prospect to be developed as potential therapeutics to treat psychiatric disorders.
\end{abstract}

\section{INTRODUCTION}

Neurodegenerative and psychiatric disorders are characterized by severe changes in brain circuitry, and recent evidences show compromised neurotrophic milieu. ${ }^{1}$ Manipulation of brain neurotrophicity with an endogenous or exogenous supply of neurotrophins has shown a potential therapeutic effect in most of these cerebral disorders. ${ }^{2}$ The exogenous administration of neurotrophins has mitigated the maladaptive changes of the brain by regulating neurite connections and neuroprotective ${ }^{3}$ as well as neurogenic ${ }^{4,5}$ properties. However, therapeutic use of exogenously supplied neurotrophins has failed to gain prominence, as it is limited by compromised pharmacokinetic properties. ${ }^{6}$ Interestingly, neurotrophic small molecules from natural or synthetic sources are successful over the exogenous neurotrophins and show good neuropharmacological efficacy in most brain disorders. ${ }^{7-9}$ Furthermore, small molecules are found to induce mood-elevating (antidepressant and anxiolytic-like) effect in rodent ${ }^{10-12}$ and zebrafish models. ${ }^{13-15}$ In this direction, we and others have focused on the exploration of novel small molecules based on diverse natural product scaffolds and their simplified analogues for neuroactive functions. ${ }^{16,17}$ This study is based on our effort in evaluating fellutamide B synthetic path intermediates for their in vitro and in vivo neuroactive properties.

Fellutamide B (a lipopeptide aldehyde) was originally isolated from Penicillium fellutanum, ${ }^{18}$ with reports of cytotoxicity $^{18}$ and potent proteasome inhibitor activity. ${ }^{19,20}$ Subsequently, fellutamide $\mathrm{B}$ was also found to induce the secretion of nerve growth factor (NGF) from fibroblasts and glioma cells. The same conditioned media has also been shown to induce neurite outgrowth activity in PC12 cells. $^{20,21}$ Considering the suggestive therapeutic potential of fellutamide $\mathrm{B}$, our group and others have been successful in its total synthesis $^{22,23}$ (synthetic approach) and also its simplified

Received: March 12, 2018

Accepted: August 17, 2018

Published: September 5, 2018 
Scheme 1. Retrosynthetic Analysis

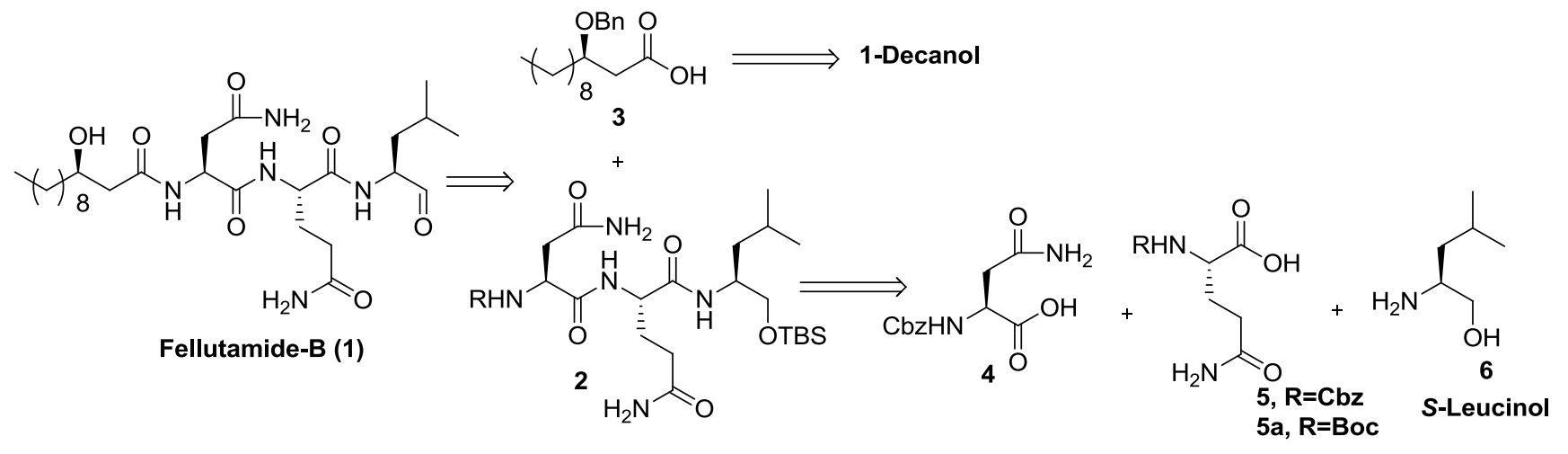<smiles>CC(C)C[C@H](C=O)NC(=O)[C@H](CCC(N)=O)NC(=O)[C@H](CC(N)=O)NC(=O)C[C@](O)(C(C)C)C(F)(F)F</smiles><smiles>CC(C)CO[C@H](CC(=O)N[C@@H](CC(N)=O)C(=O)N[C@@H](CCC(N)=O)C(=O)NC(CC(C)C)CC(C)C)C(C)C</smiles><smiles>CC(C)C[C@H](C[OH2+])NC(=O)[C@H](CCC(N)=O)NC(=O)[O-]</smiles>

A<smiles>[R5]OC[C@@H](CC(C)C)NC(=O)[C@H](CCC(N)=O)NC(=O)OCc1ccccc1</smiles>

B<smiles>CC(C)C[C@H](C[SeH])NC(=O)[C@H](CCC(N)=O)NC(=O)[C@H](CC(N)=O)NC(=O)[O-]</smiles>

C

Figure 1. Compound structures.

Scheme 2. Synthesis of Fragment 3

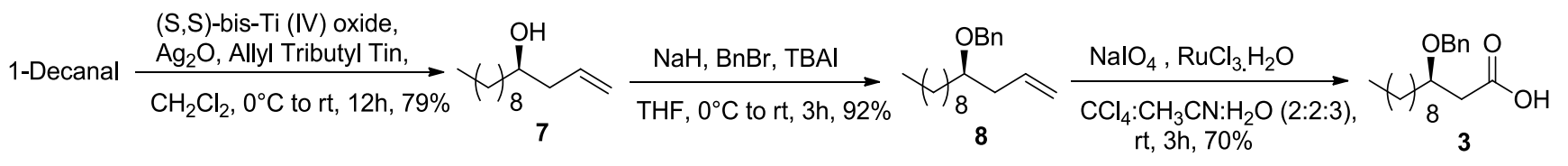

analogues. $^{24}$ The simplified analogues of fellutamide $B$ have proven equally effective in NGF induction and neurite outgrowth activity in PC12 cells. $^{24}$ Owing to its interesting structural features and biological activities, we got interested in this and reported its total synthesis ${ }^{23}$ in 2015 . Initially, it was proposed to have a 1-dodecanol long chain with benzyl protection path (in Scheme 1), but many challenges were encountered in the process. Interestingly, our attempts were rewarded with the successful synthesis of key intermediates AD (Figure 1). Inspired by the neuroactive role of fellutamide B simplified analogues, we initiated the evaluation of these fellutamide B synthetic path intermediates for their in vitro (neuritogenic), ex vivo (neurogenic), and in vivo (zebrafish behavior for antidepressant and anxiolytic-like) neuroactive functions. The study was undertaken to develop few potential neuroactive drugs based on the natural product scaffold.

\section{RESULTS}

Chemistry. The retrosynthetic approach (Scheme 1) for the target compound was planned from two key advanced intermediates, fragment 3 and tripeptide fragment 2.
Retro Synthesis. The initial route starting from natural amino acids 4, 5, 5a, and 6 and benzyl protected long chain of 1-decanol were engaged as depicted below.

In the synthesis, fragment 3 was taken up (Scheme 2) using asymmetric allylation of 1-decanal in the presence of allyltributyltin under the influence of in situ generation of $(\mathrm{S}, S)$-bis-Ti(IV)-oxide in dichloromethane at $0{ }^{\circ} \mathrm{C}$ for $12 \mathrm{~h}$, affording the homoallylic secondary alcohol 7 in $79 \%$ yield. $^{25}$ Then, treatment of 7 with $\mathrm{NaH}$ and $\mathrm{BnBr}$-mediated protection in tetrahydrofuran (THF) produced the corresponding protected alcohol 8 in $92 \%$ yield. Further oxidative cleavage ${ }^{26}$ of 8 terminal olefin in the presence of $\mathrm{NaIO}_{4}$ and $\mathrm{RuCl}_{3} \cdot \mathrm{H}_{2} \mathrm{O}$ in $\mathrm{CCl}_{4} / \mathrm{MeCN} / \mathrm{H}_{2} \mathrm{O}(2: 2: 3)$ furnished the required acid fragment 3 in $70 \%$ yield, which was immediately used for coupling reaction without further identification.

Synthesis of Fragment 3. On the other hand, to synthesize compound D (Scheme 3), S-leucinol 6 was subjected to TBSCl, $\mathrm{Et}_{3} \mathrm{~N}$-mediated protection in $\mathrm{CH}_{2} \mathrm{Cl}_{2}$, furnishing the corresponding protected amino alcohol 9 in $88 \%$ yield. Compound 9 was directly subjected to $\mathrm{N}$-(3-dimethylaminopropyl)- $N$-ethylcarbodiimide hydrochloride, 1-hydroxybenzo- 
Scheme 3. Synthesis of Fragments A-D

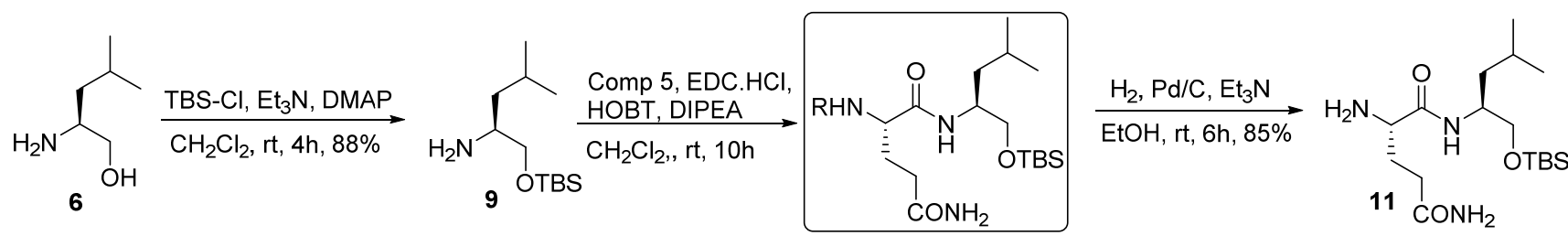

$10, \mathrm{R}=\mathrm{Cbz}=\mathrm{A} 79 \%$

$\underset{\mathrm{DMF}, \mathrm{rt}, 12 \mathrm{~h}, 82 \%}{\mathrm{Comp} \text { 4, EDC. } \mathrm{HCl}}$

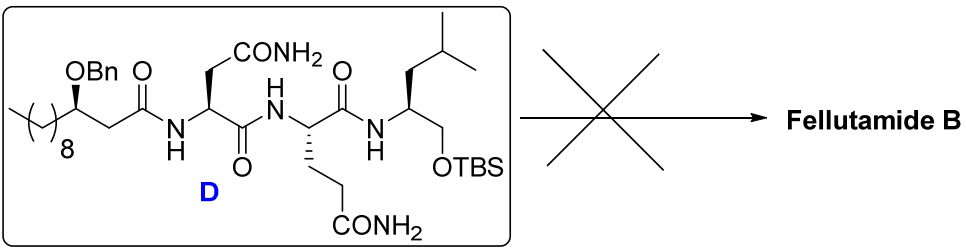

A.

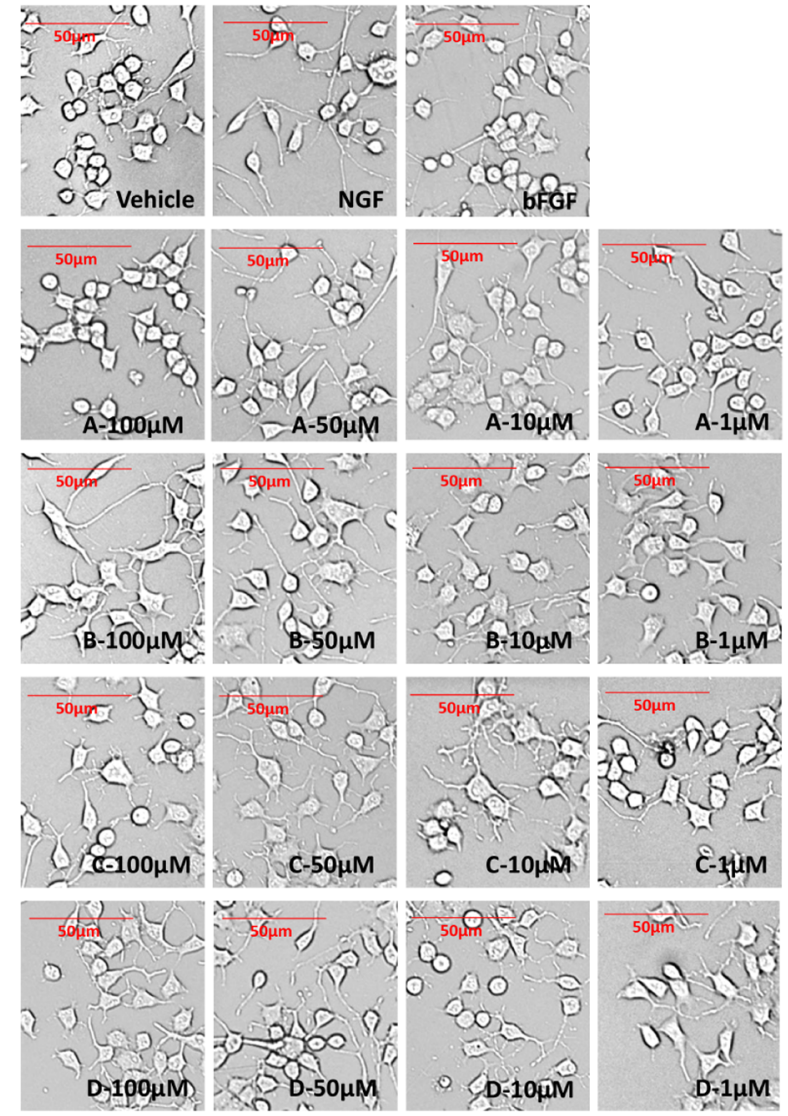

B.

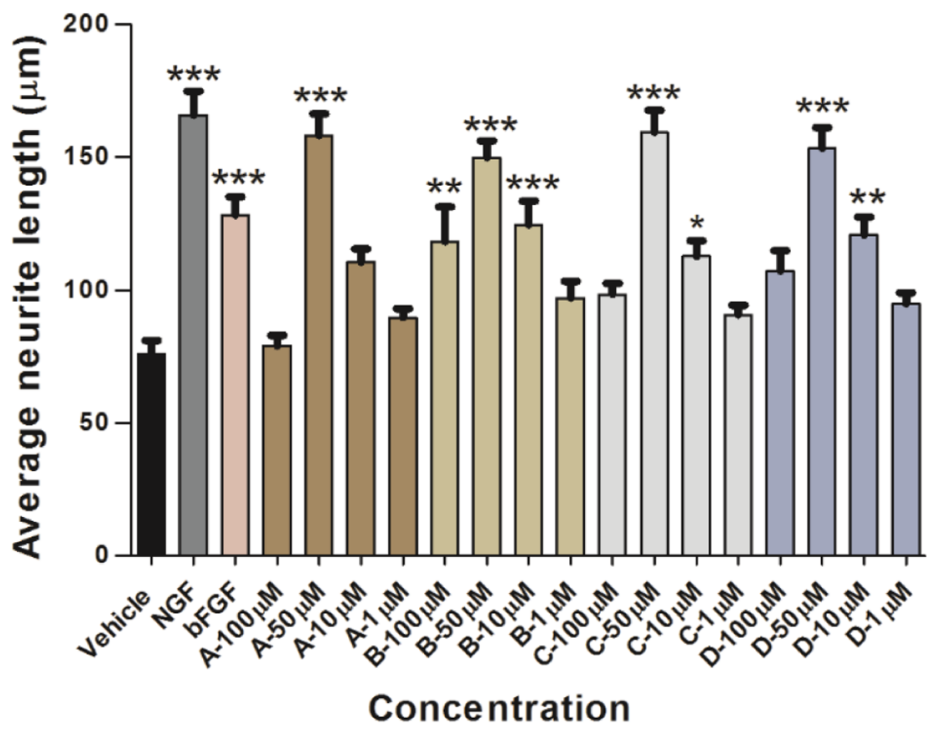

Figure 2. Compound-induced neurite outgrowth activity. (A) Bright-field images showing neurite outgrowth of compounds (comp \#A-D) at different concentrations (100-1 $\mu \mathrm{M}$ ), vehicle (1\% DMSO), and positive controls (200 ng/ $\mu \mathrm{L}-\mathrm{NGF}$ and $40 \mathrm{ng} / \mu \mathrm{L}-\mathrm{bFGF})$. (B) Bar graph showing average neurite length of compounds (comp \#A-D) at different concentrations (100-1 $\mu \mathrm{M})$. Neurites were measured using Image software on bright-field images of Neuro2a cells, taken 48 h post-treatment. $* p<0.05, * * p<0.01$, and $* * * p<0.001$ (one-way analysis of variance (ANOVA) using GraphPad Prism software) compared to vehicle (DMSO), $n=60$. 
triazole, and $i$-Pr ${ }_{2}$ NEt-mediated peptide coupling ${ }^{27,28}$ with Cbz-protected $L$-glutamine 10a and Boc-protected glutamine 5 in $\mathrm{CH}_{2} \mathrm{Cl}_{2}$ to obtain compound 10 in $79 \%$ and $10 \mathrm{a}$ in $86 \%$ yield, respectively. Hydrogenation of 10 with $10 \% \mathrm{Pd} / \mathrm{C}$ in EtOH gave compound $\mathbf{1 1}$ in $85 \%$ yield, opening the handle for the next attachment.

After purification, compound $\mathbf{1 1}$ was directly used for second peptide coupling with Cbz-protected $L$-asparagine 4 in dimethylformamide and furnished the awaited compound $\mathrm{C}$ in $82 \%$ yield. Subsequent hydrogenation of $\mathrm{C}$ using $10 \% \mathrm{Pd} / \mathrm{C}$ in EtOH produced the desired fragment 12 in $65 \%$ yield, which was directly coupled with fragment 3 to obtain compound D in $75 \%$ yield.

Finally, with compound D, debenzylation followed by oxidation of primary alcohol to aldehyde, or oxidation of primary alcohol to aldehyde followed by debenzylation, was unsuccessful to achieve target compound fellutamide B (1) in their route.

Biology. Compounds (Comp \#A-D)-Induced Neurite Outgrowth Activity in Neuro2a Cells. Fellutamide B synthetic route intermediates (comp \#A-D) (Figure 1) at different concentrations $(100-1 \mu \mathrm{M})$ were tested for neurite outgrowth activity in differentiated (serum-deprived) Neuro2a cells. Compounds (comp \#A-D) at respective optimum neuritogenic concentrations $(50 \mu \mathrm{M})$ induced significantly more neurite outgrowth (comp \#A-158.3 $\mu \mathrm{m}, \# \mathrm{~B}-149.92$ $\mu \mathrm{m}, \mathrm{AC}-159.38 \mu \mathrm{m}$, and $\mathrm{AD}-153.48 \mu \mathrm{m})(p<0.001)$ than vehicle ( $1 \%$ dimethyl sulfoxide (DMSO) $(76.13 \mu \mathrm{m})$-treated cells (Figure 2A,B). Furthermore, the optimum neurite outgrowth of (comp \#A-D) is significantly higher compared to vehicle treatment, similar to the levels observed in positive control groups: nerve growth factor (NGF) $(165.98 \mu \mathrm{m})$ and basic fibroblast growth factor (bFGF) $(128.33 \mu \mathrm{m})(p<$ 0.001) (Figure 3A,B).

Effect of Compounds (Comp \#A-D) on the Viability of Neuro2a Cells. For the potential therapeutic value, the novel compounds studied should have no toxicity. For this, the effect of compounds was assessed on the cell viability using Neuro2a cells, at the optimum neurite outgrowth concentration $(50 \mu \mathrm{M})$. The results showed no significant cytotoxicity compared to the vehicle (1\% DMSO) treatment (Figure 4).

Neurogenic Potential of Compounds (Comp \#A-D) in ex Vivo Neurosphere Assay. The neurogenesis potential has been shown to be affected in animal models of neuropsychiatric disorders, including chronic stress mod$\mathrm{els}^{29-32}$ and this potential is assessed using ex vivo neurosphere culture assay. ${ }^{33}$ Therefore, to evaluate the neurogenic ability of compounds (comp \#A-D), the hippocampi were removed from neonatal mice, and the hippocampal neural stem and/or progenitor cells (NSCs/NPCs) collected therefrom were grown in the culture medium as neurospheres. The effects of all of the compounds (comp \#A-D) were studied at various concentrations $(1.0-0.01 \mu \mathrm{M})$ for induction of neurosphere formation in NSCs/NPCs, resulting in moderately sized neurospheres $(>100 \mu \mathrm{m})$. Treatment with comp \#A, C, and D, but not \#B, at the lowest concentration tested $(0.01 \mu \mathrm{M})$ resulted in a significantly greater number of neurospheres compared to the vehicle-treated cells $(p<0.05)$ (Figure 5A,B).

Anxiolytic and Antidepressant Efficacy of Comp \#C in Chronic Stress-Induced Zebrafish Model. Since anxiety, depression, and related stress-induced mood disorders are characterized by attenuation in neurotrophic and neurogenic

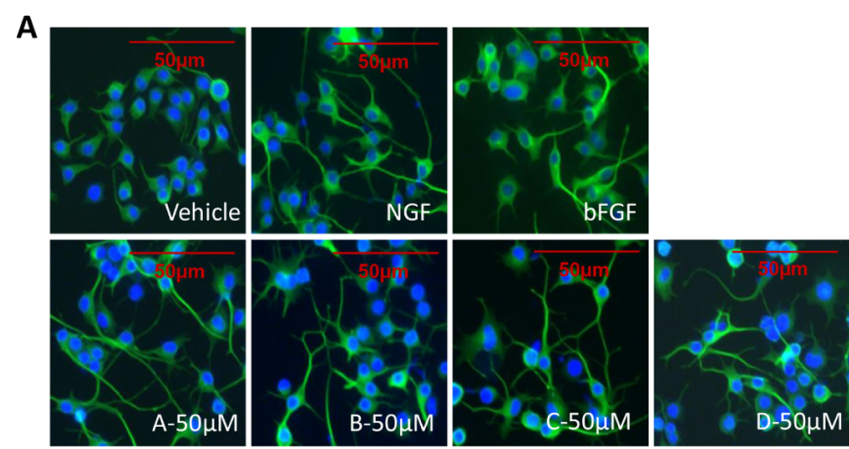

B

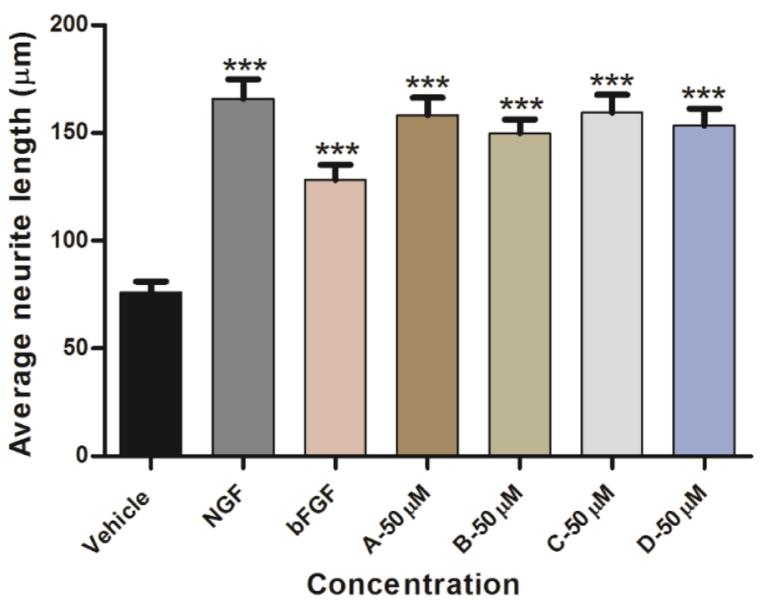

Figure 3. Compound-induced neurite outgrowth activity. (A) Immunofluorescence of Neuro2a cells with $\beta$ III tubulin antibody showing neurite outgrowth induced by compounds (comp \#A-D) at optimum neurite outgrowth concentrations $(50 \mu \mathrm{M})$, vehicle $(1 \%$ DMSO), and positive controls (200 ng/ $\mu \mathrm{L}-\mathrm{NGF}, 40 \mathrm{ng} / \mu \mathrm{L}-\mathrm{bFGF}$ ). (B) Bar graph showing average neurite length of compounds (comp \#A-D) at optimized concentrations $(50 \mu \mathrm{M}) . p<0.001$ (one-way ANOVA using GraphPad Prism software) compared to vehicle (DMSO), $n=60$.

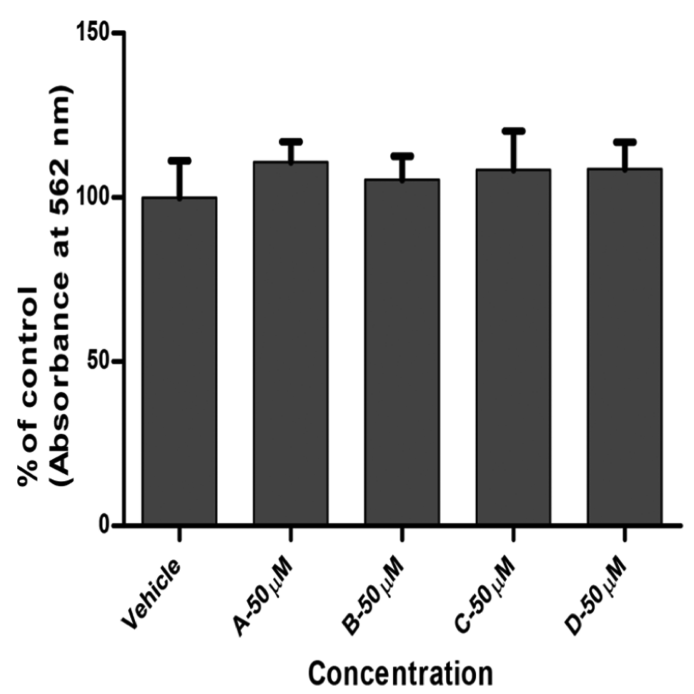

Figure 4. Bar graph showing the percentage of viable Neuro2a cells after $72 \mathrm{~h}$ incubation with the optimum neuritogenic concentration of compounds (assessed by 3-(4,5-dimethylthiazol-2-yl)-2,5-diphenyltetrazolium bromide assay, in triplicate, $p$ value not significant).

milieu, ${ }^{34-38}$ one of these highly neurotrophic and proneurogenic compounds (which induces bigger neurosphere for- 


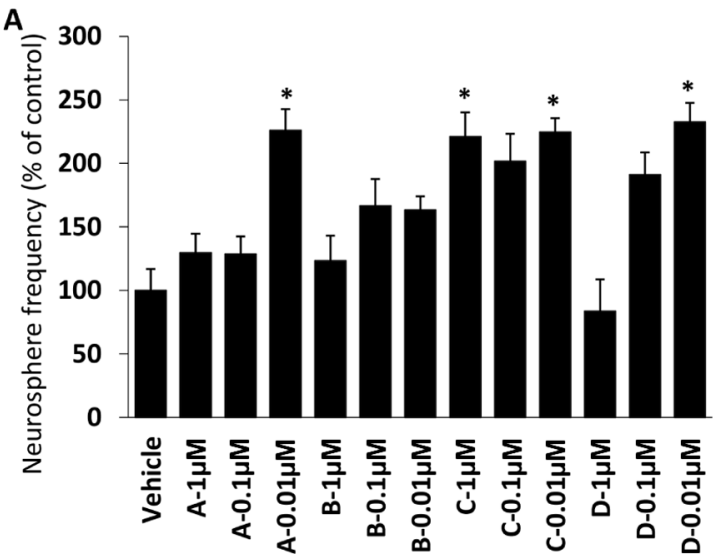

B

Figure 5. Compound-induced proliferation of neural stem/progenitor cells. (A) Corresponding bar graph displaying the frequency of neurospheres with $\geq 100 \mu \mathrm{m}$ at different concentrations of compounds, in comparison to vehicle (1\% DMSO) treatment. * $p<0.05$ compared to vehicle ( $1 \%$ DMSO), $n=3$ /group (one-way ANOVA using GraphPad Prism software). (B) Bright-field images of vehicle (1\% DMSO) and compound-treated (comp \#A-D at $0.01 \mu \mathrm{M}$ ) culture showing the prevalence of neurosphere formation.
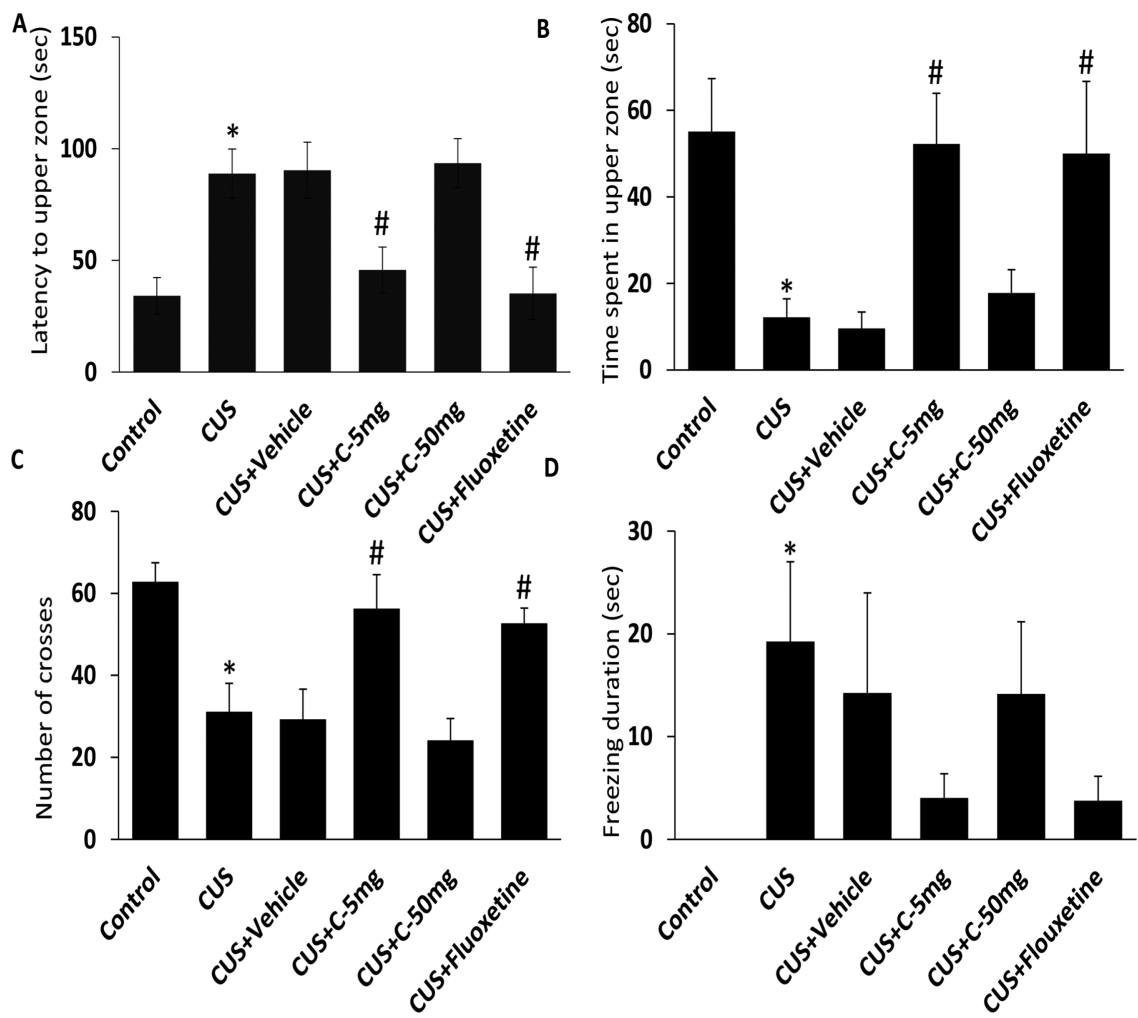

Figure 6. Novel tank test. (A-D) Comp \#C ( $5 \mathrm{mg}$ and $50 \mathrm{mg} / \mathrm{kg}$ )- and fluoxetine $(15 \mathrm{mg} / \mathrm{kg})$-induced behavioral changes in novel tank test. (A) Latency to upper zone (seconds); (B) total time spent in the upper zone (seconds); (C) number of crosses; and (D) freezing duration (seconds). $n$ $=12, * p<0.05$ compared to the control group (Student's $t$-test), ${ }^{\#} p<0.05$ compared to CUS + vehicle group (one-way ANOVA using GraphPad Prism software).

mation), comp \#C, was tested in vivo in zebrafish mood disorder model. To assess the anxiolytic and antidepressantlike effect of comp \#C, novel tank test (NTT) and social interaction test were performed using chronic unpredictable stress (CUS)-induced zebrafish anxiety and related mood disorder model, ${ }^{39}$ as described in detail in the Experimental section. Before treatment with the compound, the animals were exposed to CUS paradigm, and the data from NTT and social interaction test were analyzed to see whether CUS induces a phenotypic response (i.e., anxiety- and depressionlike condition). Anxiety-like phenotype was observed as assessed in NTT, such as significantly higher latency to reach upper zone, less amount of time spent in the upper zone, decreased number of crosses by animals, and high freezing duration $(p<0.05)$ (Supplementary Figure 1A-D). Depression-like phenotype was clearly observed after assessing the animals in the social interaction test; zebrafish subjected to CUS exhibited remarkably less time in interaction with the target fish $(p<0.05)$ (Supplementary Figure 2A) and showed increase in total freezing duration, too, another hallmark of depressed fish $(p<0.05)$ (Supplementary Figure 2B). Once the fish started showing mood disorder phenotype, the animals 
A

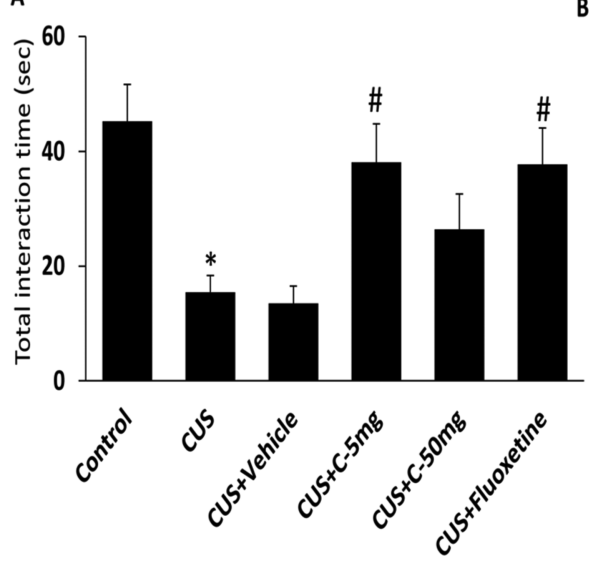

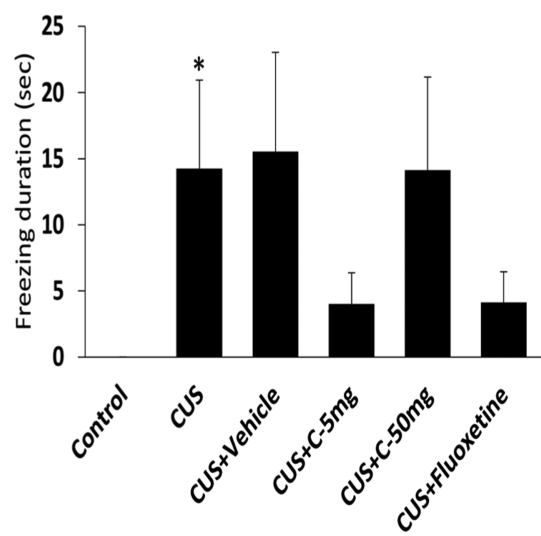

Figure 7. Social interaction test. (A, B) Comp \#C (5 mg and $50 \mathrm{mg} / \mathrm{kg})$ - and fluoxetine $(15 \mathrm{mg} / \mathrm{kg})$-induced behavioral changes in social interaction test. (A) Total interaction time (seconds) and (B) freezing duration (seconds). $n=12, * p<0.05$ compared to the control group (Student's $t$-test), ${ }^{\#} p<0.05$ compared to CUS + vehicle group (one-way ANOVA using GraphPad Prism software).

were divided into different groups and treated with vehicle, comp $\# \mathrm{C}$, and the antidepressant fluoxetine, the positive control, as described below.

Novel Tank Test. Zebrafish were subjected to CUS, followed by treatment with vehicle, comp \#C at 5 and 50 $\mathrm{mg} / \mathrm{kg}$ dose, and the antidepressant fluoxetine, positive control, and the behavior data from the NTT were analyzed. CUS resulted in higher latency to the upper zone (Figure 6A), indicating anxiety-like condition. The high latency to upper zone in the CUS group was restored to the level observed in control unstressed animals upon treatment with the lower dose of comp \#C $(5 \mathrm{mg} / \mathrm{kg})$ and fluoxetine $(p<0.05)$; the vehicle treatment group still had higher latency as in CUS group (Figure 6A).

On analyzing another parameter in the NTT, i.e., the total time spent in the upper zone of the novel tank, CUS led to significantly less time spent in the upper zone (Figure 6B), indicating anxiety. This feature was restored back to control level upon treatment with comp \#C (at $5 \mathrm{mg} / \mathrm{kg}$ dose and not $50 \mathrm{mg}$ ) as well as fluoxetine, i.e., increase in time spent in the upper zone (Figure 6B). The same trend was observed when another parameter, i.e., number of crosses, was analyzed (Figure 6C). Previous studies have shown freezing during the NTT in stressed zebrafish, indicating mood disorder. ${ }^{39,40}$ Our analysis along similar lines in total freezing duration in all of the groups does not show a significant difference between the groups, rather suggesting a trend in the same direction as seen in the anxiety parameter, latency to upper zone, described above (Figure 6D).

Social Interaction Test. Comp \#C was administered at 5 and $50 \mathrm{mg} / \mathrm{kg}$ dose to CUS-subjected fish, and the efficacy on depression-like behavior was assessed through the social interaction test. Compound-induced changes in the total time spent in the interaction zone and in freezing behavior were recorded. The group treated with comp \#C at $5 \mathrm{mg} / \mathrm{kg}$, but not $50 \mathrm{~g} / \mathrm{kg}$ dose, showed remarkably more time spent in the interaction zone like the fluoxetine-treated group compared to the vehicle-treated group $(p<0.05)$ (Figure 7A). Furthermore, comp \#C $(5 \mathrm{mg} / \mathrm{kg}$, but not $50 \mathrm{~g} / \mathrm{kg})$-treated group has shown a decreased trend in the freezing duration (not statistically significant), similar to that observed in the fluoxetine (15 mg/kg)-treated group (Figure $7 \mathrm{~B}$ ).
Efficacy of Comp \#C on Gene Expression of an Important Neurotrophin Brain (BDNF)-Derived Neurotrophic Factor. From the neurotrophin or neurotrophic factor family, BDNF has been shown to play a critical role in maintaining proper neural functions. ${ }^{38,41,42}$ An attenuation in its level in brain circuitry is observed in animal models of neuropsychiatric disorders, including depression, anxiety, and related mood disorders. ${ }^{4-45}$ The treatment of animal models with antidepressants and anxiolytics has been shown to increase its level in the affected circuitry. ${ }^{46,47}$ Therefore, the change in the level of BDNF gene expression in the telencephalon of stress-exposed zebrafish was assessed after the treatment with comp \#C ( 5 and $50 \mathrm{mg} / \mathrm{kg}$ doses) and the positive control fluoxetine $(15 \mathrm{mg} / \mathrm{kg})$, the most prescribed antidepressant. Interestingly, only at low doses (compared to vehicle group) comp \#C increased the level of BDNF gene expression $(p<0.05)$ in the brain area investigated, similar to the fluoxetine-treated group (Figure 8).

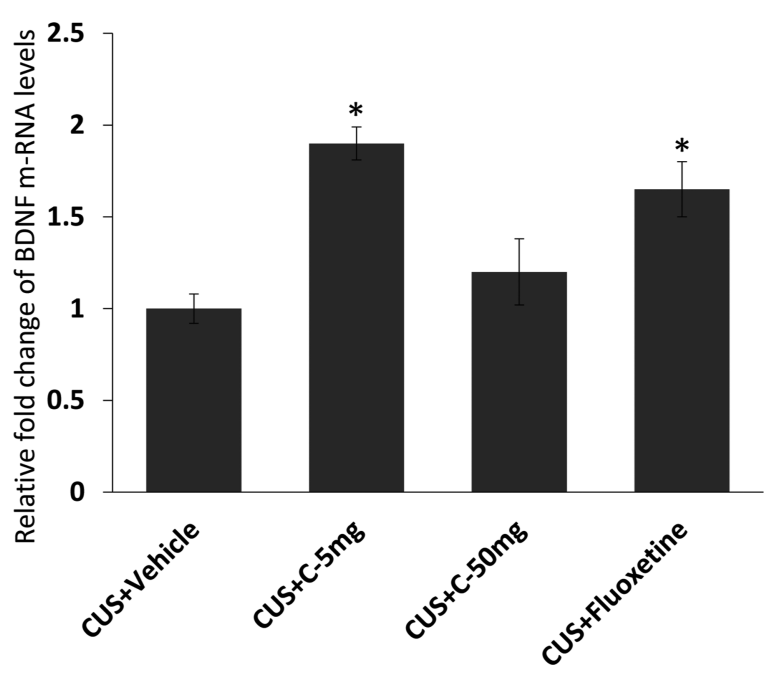

Figure 8. Real-time polymerase chain reaction (PCR) data. Induction of mRNA transcript levels of neurotrophic factor gene (BDNF) by comp \#C (5 and $50 \mathrm{mg} / \mathrm{kg}$ ), fluoxetine $(15 \mathrm{mg} / \mathrm{kg}$ ), and CUS + vehicle groups in the telencephalon of CUS-subjected zebrafish, normalized with GAPDH. * $p<0.05$ (one-way ANOVA using GraphPad Prism software) compared to CUS + vehicle group. 


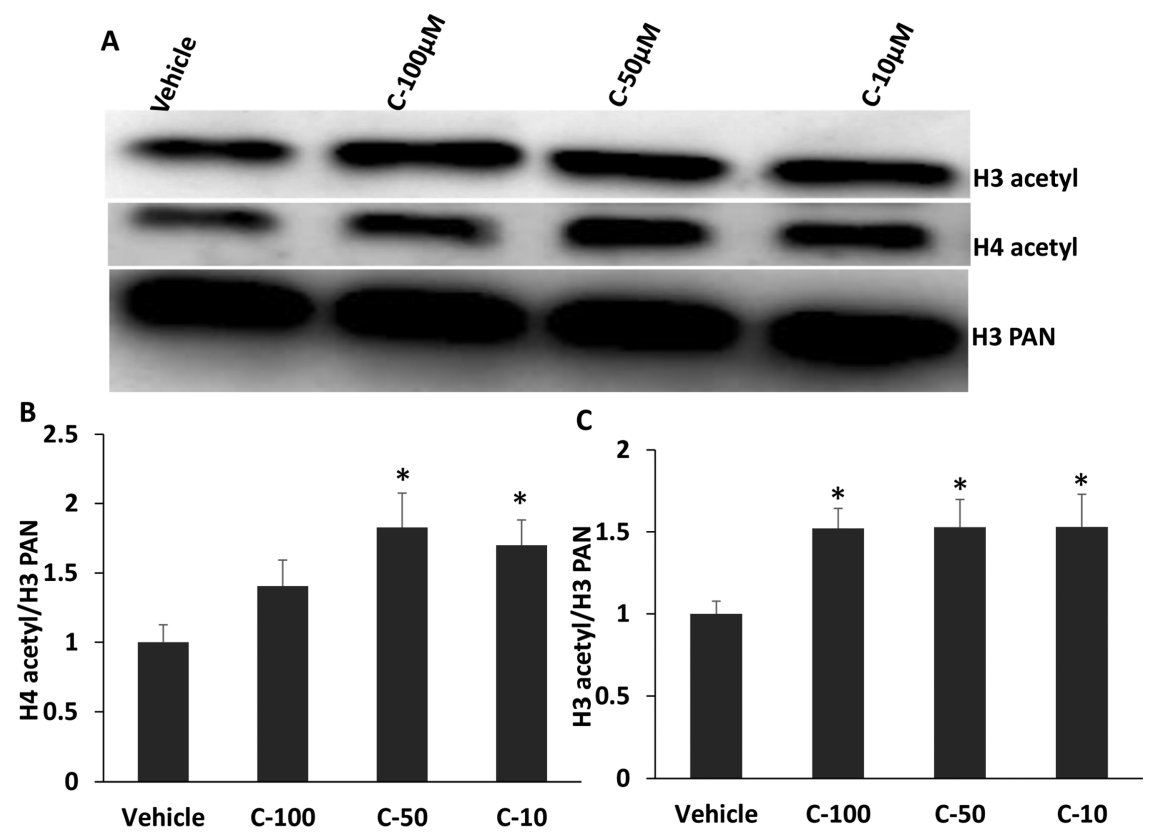

Figure 9. Immunoblot data. (A) Immunoblot data showing the levels of $\mathrm{H} 3$ acetyl, $\mathrm{H} 4$ acetyl, and $\mathrm{H} 3 \mathrm{PAN}$ upon comp \#C treatment (100, 50, and $10 \mu \mathrm{M}$ ) in Neuro2a cells for $2 \mathrm{~h}$ incubation. (B, C) Bar graph showing the densitometry values for $\mathrm{H} 3$ acetyl, $\mathrm{H} 4$ acetyl, and $\mathrm{H} 3 \mathrm{PAN}$ of the immunoblot. $n=3, * p<0.05$ (Student's t-test) compared to vehicle treatment.

Compound-Induced Histone $\mathrm{H} 3$ and $\mathrm{H} 4$ Acetylation Changes in Neuro2a Cells. Recent studies show the involvement of histone acetylation-based epigenetic mechanisms in brain circuitry that gets affected in animal models of chronic stress-induced depression, anxiety, and related disorders. $^{10,48}$ Attenuation of histone $\mathrm{H} 3$ and/or $\mathrm{H} 4$ acetylation is associated with compromised neurotrophic and neurogenic features, including BDNF downregulation in animal models of neuropsychiatric disorders, where increasing acetylation levels has shown amelioration in the condition. ${ }^{49-52}$ Keeping this in mind, we assessed the change in $\mathrm{H} 3$ and $\mathrm{H} 4$ acetylation levels in differentiated mouse neuroblastoma cell line Neuro2a after the comp \#C treatment. Treatment of cells with neuritogenic concentrations of comp \#C $(100,50$, and $10 \mu \mathrm{M})$ resulted in an increased level of acetyl H3 (Figure 9A,C). In addition, comp \#C (50 and 10 $\mu \mathrm{M}$ ) significantly induced the acetylated $\mathrm{H} 4$ level in Neuro2a cells compared to vehicle (DMSO) treatment (Figure 9A,B). We have also observed increased acetylation levels of $\mathrm{H} 3$ and $\mathrm{H} 4$ at neurogenic concentrations of comp \#C in undifferentiated IMR32 cells (Supplementary Figure 3).

\section{DISCUSSION}

Most of the neuropsychiatric disorders, including depression, anxiety, and related mood disorders, are associated with attenuation in neurotrophic and neurogenic activity. ${ }^{53-56}$ Therefore, laboratories across the world are trying to develop small molecules of natural and synthetic origin with the ability to promote neurite outgrowth and neurogenesis for developing therapeutics to treat these brain and behavioral disorders. In this direction, we too have focused on developing repertoires of neuroactive simplified small molecules based on natural product scaffolds. Fellutamide B is one such promising molecule that gained prominence owing to its neurotrophic activity, ${ }^{20,21}$ in addition to its other bioactive properties. ${ }^{18,19}$ Other groups have recently synthesized fellutamide B and its simplified analogues and showed their neurite growth- enhancing activity. ${ }^{19}$ These reports led us to synthesize fellutamide $\mathrm{B}$, and in this process, we got rewarded with four intermediate products, compounds A-D (shown in Figure 1), which interestingly showed good neurotrophic or neurite growth-promoting activity in Neuro2a cells, at levels similar to those reported by others for fellutamide B and its analogues. Thereafter, these compounds were tested for neurogenic potential in ex vivo neurosphere assay. Except for comp \#B, most of these small molecules showed potent neurogenic activity in mouse hippocampal neural stem/progenitor cells (Figure $5 \mathrm{~A}, \mathrm{~B}$ ), as much as was shown by few diverse naturally derived small molecules ${ }^{57,58}$ and their scaffolds ${ }^{8}$ that have been recently reported by us.

Finally, using zebrafish CUS model for depression and related mood disorders, ${ }^{39,59-61}$ where both neurotrophic and neurogenic activities are compromised, one of these potent intermediate compounds, comp \#C, showed potent moodelevating role as an anxiolytic and antidepressant. To our knowledge, we are the first to report small molecules sharing structure similarity with fellutamide B that have remarkable therapeutic potential in depression and related mood disorders. This in vivo effect of comp \#C appears to be in part due to BDNF induction in the zebrafish telencephalon. Since comp \#C also acts epigenetically (as shown by its enhancing effect on $\mathrm{H} 3$ and $\mathrm{H} 4$ acetylation in mouse neuroblastoma cell line Neuro2a), we suggest that the mood-elevating effects of this novel compound could partly be attributed to its epigenetic action, too.

In conclusion, we have demonstrated that novel smallmolecule pathway intermediates of fellutamide B are interesting compounds with potent neurotrophic and neurogenic actions. One of these, i.e., comp \#C, also showed robust mood-elevating effects in a zebrafish CUS mood disorder model by enhancing the levels of the critical neurotrophin BDNF, owing to which it can be taken up for the next level of preclinical drug discovery. In future, designing of analogues around the comp \#C structural framework might lead us to 
identify more potential novel small molecules for developing therapeutics to treat depression and related mood disorders.

\section{EXPERIMENTAL SECTION}

Chemistry. All of the chemicals were purchased from Sigma-Aldrich and were directly used without further purification; anhydrous reactions were performed in ovendried round-bottom flasks under a dry argon atmosphere. Air and moisture-sensitive compounds were introduced via syringes or cannulae using standard inert atmosphere techniques. Reactions were monitored by thin-layer chromatography (TLC) using E. Merck silica gel plates, and components were visualized by illumination with shortwavelength UV light and/or staining (ninhydrin, $p$-anisaldehyde, or basic $\mathrm{KMnO}_{4}$ ). All reagents were used as they were received from commercial suppliers, unless otherwise noted. Technical-grade ethyl acetate, hexanes, chloroform, and methanol used for column chromatography were distilled prior to use. THF and $\mathrm{Et}_{2} \mathrm{O}$ were dried in the presence of sodium metal using benzophenone as an indicator and distilled prior to use. Anhydrous $\mathrm{CH}_{2} \mathrm{Cl}_{2}$ was prepared by refluxing in the presence of $\mathrm{CaH}_{2}$ and distilled right before use. Optical rotations were measured with a digital polarimeter using a 2 $\mathrm{mL}$ cell with a $1 \mathrm{dm}$ path length. Fourier transform infrared spectra were recorded as $\mathrm{KBr}$ disks or neat. The ${ }^{1} \mathrm{H}$ and ${ }^{13} \mathrm{C}$ NMR spectra were recorded in $\mathrm{CDCl}_{3}$ or DMSO- $d_{6}$ on 300 and $500 \mathrm{MHz}$ spectrometers. The residual peak of $\mathrm{CHCl}_{3}$ was set at $7.26 \mathrm{ppm}$ for ${ }^{1} \mathrm{H}$ NMR spectroscopy, and the central peak of $\mathrm{CDCl}_{3}$ was set at $77.0 \mathrm{ppm}$ for ${ }^{13} \mathrm{C}$ NMR spectroscopy. All products were purified by flash column chromatography on silica gel (60-120 mesh and 100-200 mesh).

Cell Culture Maintenance. Neuro2a (mouse neuroblastoma) and IMR32 (human neuroblastoma) cell lines were procured from the American Type Culture Collection. These cell lines (Neuro2a and IMR32) were maintained in complete media containing Dulbecco's modified Eagle's medium (DMEM) supplemented with $10 \%$ fetal bovine serum (FBS) (Gibco), penicillin/streptomycin (1\%), sodium pyruvate $(1 \times)$, and nonessential amino acids solution $(1 \times)$, at $37^{\circ} \mathrm{C}$ in a humidified atmosphere supplemented with $5 \% \mathrm{CO}_{2}$. For differentiation experiments, cells were grown in culture media with reduced serum (DMEM $+1 \%$ FBS).

Neurite Outgrowth Assay. Neurite outgrowth activity assay was performed as reported. ${ }^{62}$ Briefly, Neuro2a cells were seeded at low density $\left(8000\right.$ cells $\left./ \mathrm{cm}^{2}\right)$ in six-well plates. After $24 \mathrm{~h}$, the cells were allowed to differentiate in culture media containing reduced serum levels (DMEM $+1 \%$ FBS). After 6 $\mathrm{h}$, the cells were incubated with different concentrations of compounds (100-1 $\mu \mathrm{M})$ and were observed for neurite outgrowth activity. Bright-field images of Neuro2a cells treated with different concentrations of compounds were used to measure the neurite outgrowth activity. The cells were then fixed with $4 \%$ paraformaldehyde in $1 \times$ phosphate-buffered saline (PBS) and used for immunocytochemical studies. To evaluate the compound-induced neurite growth changes, the average neurite length for each treatment was measured (using ImageJ software) considering 60 neurons from six microscopic fields that randomly captured two images per well from three independent experiments.

Cell Viability Assay. The cell viability assay was performed as previously reported ${ }^{62}$ to assess the effects of compounds on cell viability in Neuro2a cells.
Neurosphere Assay. The neurosphere assay was performed as published previously ${ }^{16}$ to evaluate the neurogenic potential of compounds.

Immunocytochemistry. Neuro2a and IMR32 cells, incubated with different concentrations of compounds, were processed for the immunostaining following our earlier protocol. ${ }^{38,62}$ Briefly, fixation of the cells after incubation with different treatments has been done with $4 \%$ paraformaldehyde at room temperature for $15 \mathrm{~min}$. It is followed by permeabilization with $0.5 \%$ Triton X-100 and $0.05 \%$ Tween 20 in $1 \times$ PBS, then incubation for $2 \mathrm{~h}$ at room temperature in blocking buffer $(2 \%$ bovine serum albumin $+0.1 \%$ Triton $\mathrm{X}$ 100 in $1 \times$ PBS). Primary antibodies against $\beta$ III tubulin (1:200, Millipore), H3 acetylation (1:100), and $\mathrm{H} 4$ acetylation (1:100) were used. The samples were incubated overnight at 4 ${ }^{\circ} \mathrm{C}$ with primary antibody in the blocking buffer. The samples were washed with PBST (PBS with $0.1 \%$ Tween 20) and incubated with goat antimouse IgG conjugated to AlexaFlour 488 (1:400, Molecular Probes) and anti-rabbit Cy3 (1:1000). A Motic AE31 microscope was used for capturing the cell images.

Immunoblot. Neuro2a cells were treated with different concentrations of compounds and vehicle. The cells incubated with different treatments were washed with $1 \times$ PBS and harvested in $1 \times$ laemmli sample buffer. The cell lysate total protein relative concentration estimated with amido black method and an equal amount of protein was loaded onto $12 \%$ sodium dodecyl sulfate-polyacrylamide gel electrophoresis gel. Blocking was done for $1 \mathrm{~h}$ at room temperature, followed by incubation with primary antibodies $\mathrm{H} 3$ acetyl (1:1000), H4 acetyl (1:2000), and H3 PAN (1:3000) overnight at $4{ }^{\circ} \mathrm{C}$. The blots were washed with $1 \times \mathrm{PBST}$, and incubation in secondary antibody anti-rabbit (1:5000) was done at room temperature for $1 \mathrm{~h}$. The blots were again washed with $1 \times$ PBST and then developed with the Bio-Rad ChemiDoc instrument using WesternBright ECL solution (advansta). The band intensities of Western blots were measured using ImageJ software.

RNA Isolation and Gene Expression Analysis by RealTime Quantitative PCR (qPCR). Total RNA was isolated from telencephalon brain regions pooled from four zebrafish brain and stored at $-80{ }^{\circ} \mathrm{C}$. Total RNA isolation, deoxyribonuclease I enzyme treatment, cDNA synthesis, and qPCR were performed according to the previously published protocol. ${ }^{63}$ The expression levels of BDNF and the housekeeping or reference gene GAPDH were measured using qPCR. After normalization with the transcript levels of GAPDH, the fold change in the BDNF transcript was calculated using the $\Delta \Delta \mathrm{Ct}$ methods. The GAPDH Ct values were stable in all of the conditions and experiments. The primers used for qPCR analysis were (BDNF F-ATAGGGGAAAATGTTCCAACAGG, R-CCCGGGATCTCTCTCATGG) (GAPDH F-GAGGCTTCTCACAAACGAGGA, R-TGGCCACGATCTCCACTTTC).

Animals and Housing. Adult zebrafish (Danio rerio) bred and raised in captivity were used for the behavioral and molecular experiments. The zebrafish used for the experiments were raised in large tanks with a natural day light/dark cycle and two feedings, until they arrived in the laboratory. In the fish facility of the lab, zebrafish procured were acclimatized to the experimental room conditions by maintaining them at $28 \pm$ $2{ }^{\circ} \mathrm{C}, 14 / 10 \mathrm{~h}$ light/dark cycle, three feedings, and constant aeration. After the habituation period, the fish were separated into two groups as control and test sets and the test animals 
were subjected to two different stressors per day for a period of 7 days. Fish that exhibited stress-induced phenotypic changes, assessed by novel tank test and social interaction test, were treated intraperitoneally for 4 days with the indicated dose: comp \#C 5, $50 \mathrm{mg} / \mathrm{kg}$, and fluoxetine, $15 \mathrm{mg} / \mathrm{kg}$. Following the behavioral testing (before and after the compound and positive control fluoxetine treatment), all fish were euthanized and the telencephalon regions were immediately dissected out and stored at $-84{ }^{\circ} \mathrm{C}$ for further studies. All animal procedures were done according to the protocol approved by the Institutional Animal Ethics Committee (IAEC/IICT/Protocol No.26/2016).

Chronic Unpredictable Stress (CUS) Paradigm in Zebrafish. CUS paradigm to induced depression, anxiety, and related mood disorder phenotype was performed with small modifications to the previously published protocol. ${ }^{39}$ For a period of 7 days, the fish were subjected to a variety of chronic stressors with two stressors per day (forenoon and afternoon), such as restrain stress (RS), heat stress (HS), cold stress (CS), social isolation (SI), overcrowding (OC), predator stress (PS), dorsal body exposure (DBE), tank change (TC), chasing (C), and alarm pheromone stress (APS). Restrain stress (RS): each animal was restrained for $1 \mathrm{~h}$ in a $2 \mathrm{~mL}$ microcentrifuge tube with perforations at both the ends for free water flow; heat stress (HS) and cold stress (CS): animals were transferred to new tanks maintained at 33 and $23{ }^{\circ} \mathrm{C}$, respectively, for $30 \mathrm{~min}$; social isolation (SI): in separate beakers for $60 \mathrm{~min}$; overcrowding (OC): 10 animals in a 250 $\mathrm{mL}$ beaker containing only $150 \mathrm{~mL}$ of water, for $60 \mathrm{~min}$; predator stress (PS): test animals exposed to predators' (cichlid fish) encounters (chases and attacks) for $1 \mathrm{~min}$; dorsal body exposure (DBE): animals in housing tanks with low water level to expose the animal dorsal body for $2 \mathrm{~min}$; tank change (TC): transferred from one tank to another about six consecutive times; chasing (C): chased with a net for 8 min; and alarm pheromone stress (APS): the test fish was exposed for about $30 \mathrm{~min}$ to water containing the washing of epidermal cells from the euthanized/sliced zebrafish. To avoid habituation to stressors, unpredictability was maintained by changing the time and sequence of stressors daily, during 7 days of the stress paradigm. Aeration and temperature were controlled during the presentation of each stressor, except during heating and cooling stress. The nonstressed control group was maintained in the same room during the 7 day stress period.

Behavior Test. Novel Tank Test (NTT). NTT was performed as previously reported. ${ }^{39}$ Briefly, zebrafish were placed individually in a narrow $15 \times 12 \times 25 \mathrm{~cm}^{3}$ tank with a water depth of $18 \mathrm{~cm}$, which is divided into three equal horizontal sections (bottom, middle, and upper zones) with virtual lines. In the 2 min novel tank test, the time spent by the fish in different levels of the tank (bottom, middle, or upper level) was measured to assess the level of anxiety. A preference for the tank bottom and less frequent venturing in and time spent in the middle and upper levels of the tank is suggestive of increased anxiety. Similarly, longer latency to enter the middle and upper levels of the tank, less number of crosses (measure of exploratory drive), and high freezing duration are indicative of anxiety and related behavior phenotype.

Social Interaction Test. It is well reported that depression affects the social behavior of the animals exposed to chronic stressful conditions. ${ }^{64}$ The social avoidance behavior of the stressed zebrafish, indicative of depression-like phenotype, was assessed by the social interaction test based on the approach and interaction behavior toward an unfamiliar conspecific target (pink-colored zebrafish) as reported. ${ }^{33}$ Briefly, experimental zebrafish were introduced into the tank with the target in the interaction box for $120 \mathrm{~s}$, a conspecific pink-colored zebrafish served as a target animal in the interaction zone. The entire test was video-recorded with a Sony Handycam Camcorder 200E in HD mode, and the data were scored manually. The depression-like phenotype was assessed by evaluating the duration of interaction and also the freezing duration.

Statistical Analysis. The results were expressed as mean \pm standard error of the mean from three independent experiments. Data were appropriately subjected to either two-tailed paired Student's $t$-test or ANOVA, followed by Tukey's post hoc analysis, using GraphPad Prism software. A value of $p<$ 0.05 was considered statistically significant.

\section{ASSOCIATED CONTENT}

\section{Supporting Information}

The Supporting Information is available free of charge on the ACS Publications website at DOI: 10.1021/acsomega.8b00456.

${ }^{1} \mathrm{H}$ and ${ }^{13} \mathrm{C}$ spectra of compounds; novel tank test (before the treatment with a novel compound as well as with the positive control drug fluoxetine) in control and chronic unpredictable stress (CUS)-induced zebrafish (Supplementary Figure 1); social interaction test (before the treatment with compound and the positive control drug fluoxetine) in control and chronic unpredictable stress (CUS)-induced zebrafish (Supplementary Figure 2); and immunocytochemistry for acetyl $\mathrm{H} 3$, acetyl $\mathrm{H} 4$, and DAPI in IMR32 cells subjected to compound treatment (Supplementary Figure 3) (PDF)

\section{AUTHOR INFORMATION}

\section{Corresponding Authors}

*E-mail: saibal@iict.res.in. Tel: +91 04027191887 (S.D.).

*E-mail: sumanachak@iict.res.in. Tel: +91 040 27191856. Fax: 04027193189 (S.C.).

\section{ORCID}

Sumana Chakravarty: 0000-0001-8223-6508

\section{Present Addresses}

Neuroscience Research, Barker Street, Randwick, NSW 2031, Australia (S.K.).

${ }^{\circ}$ Laboratory of Genetics and Autoimmunity, VIB-KU Leuven Center for Brain and Disease Research, 3000 Leuven, Belgium (W.D.R.).

${ }^{\nabla}$ Pharmaceutical Sciences, College of Pharmacy, The University of Arkansas for Medical Sciences, Little Rock, Arkansas 72205, United States (S.S.D.).

${ }^{\#}$ Centre for Cellular and Molecular Biology (CCMB), Hyderabad 500007, India (R.G.R.).

\section{Author Contributions}

${ }^{\perp}$ R.G.R. and S.S.D. contributed equally to this work.

\section{Author Contributions}

S.C., S.D., A.K., R.G.R., and S.S.D. designed the experiments. S.S.D., K.B.K., and S.D. designed and synthesized the novel compounds. R.G.R., B.R.R., W.D.R., S.K., and S.C. performed the biological experiments. S.C., S.D., A.K., R.G.R., and S.S.D. analyzed the results. S.C. supervised all of the biological 
experiments performed in the study. S.C., S.D., A.K., R.G.R., and S.S.D. wrote the paper and all authors reviewed and edited it.

\section{Notes}

The authors declare no competing financial interest.

\section{ACKNOWLEDGMENTS}

This study was initiated under the Indo-French "Joint Laboratory for Sustainable Chemistry at Interfaces" and "Joint Laboratory for Natural Products and Synthesis towards Affordable Health (NPSAH)" to S.C. and S.D. Then latter was supported by the Council of Scientific and Industrial Research (CSIR) under network projects (BSC0103-UNDO to S.C. and A.K.). R.G.R., S.S.D., B.R.R., K.B.K., W.D.R., and S.K. acknowledge CSIR and DBT, India, for the award of research fellowships.

\section{REFERENCES}

(1) Nagahara, A. H.; Tuszynski, M. H. Potential therapeutic uses of BDNF in neurological and psychiatric disorders. Nat. Rev. Drug Discovery 2011, 10, 209-219.

(2) Mitre, M.; Mariga, A.; Chao, M. V. Neurotrophin signalling: novel insights into mechanisms and pathophysiology. Clin. Sci. 2017, 131, 13-23.

(3) Chaturvedi, R. K.; Shukla, S.; Seth, K.; Agrawal, A. K. Nerve growth factor increases survival of dopaminergic graft, rescue nigral dopaminergic neurons and restores functional deficits in rat model of Parkinson's disease. Neurosci. Lett. 2006, 398, 44-49.

(4) Emsley, J. G.; Hagg, T. Endogenous and exogenous ciliary neurotrophic factor enhances forebrain neurogenesis in adult mice. Exp. Neurol. 2003, 183, 298-310.

(5) Zigova, T.; Pencea, V.; Wiegand, S. J.; Luskin, M. B. Intraventricular administration of BDNF increases the number of newly generated neurons in the adult olfactory bulb. Mol. Cell. Neurosci. 1998, 11, 234-245.

(6) Beck, M.; Flachenecker, P.; Magnus, T.; Giess, R.; Reiners, K.; Toyka, K. V.; Naumann, M. Autonomic dysfunction in ALS: a preliminary study on the effects of intrathecal BDNF. Amyotrophic Lateral Scler. 2005, 6, 100-103.

(7) Zhang, Z.; Liu, X.; Schroeder, J. P.; Chan, C.-B.; Song, M.; Yu, S. P.; Weinshenker, D.; Ye, K. 7,8-Dihydroxyflavone prevents synaptic loss and memory deficits in a mouse model of Alzheimer's disease. Neuropsychopharmacology 2014, 39, 638-650.

(8) Joshi, P. C.; Samineni, R.; Bhattacharya, D.; Reddy, B. R.; Veeraval, L.; Das, T.; Maitra, S.; Wahul, A. B.; Karri, S.; Pabbaraja, S.; et al. A 2-oxa-spiro [5.4] decane scaffold displays neurotrophic, neurogenic and anti-neuroinflammatory activities with high potential for development as a versatile CNS therapeutic. Sci. Rep. 2017, 7, No. 1492.

(9) Chen, J.; Zhang, C.; Jiang, H.; Li, Y.; Zhang, L.; Robin, A.; Katakowski, M.; Lu, M.; Chopp, M. Atorvastatin induction of VEGF and BDNF promotes brain plasticity after stroke in mice. J. Cereb. Blood Flow Metab. 2005, 25, 281-290.

(10) Tsankova, N. M.; Berton, O.; Renthal, W.; Kumar, A.; Neve, R. L.; Nestler, E. J. Sustained hippocampal chromatin regulation in a mouse model of depression and antidepressant action. Nat. Neurosci. 2006, 9, 519-525.

(11) Liu, X.; Chan, C.-B.; Jang, S.-W.; Pradoldej, S.; Huang, J.; He, K.; Phun, L. H.; France, S.; Xiao, G.; Jia, Y.; et al. A synthetic 7,8dihydroxyflavone derivative promotes neurogenesis and exhibits potent antidepressant effect. J. Med. Chem. 2010, 53, 8274-8286.

(12) Hurley, L. L.; Akinfiresoye, L.; Kalejaiye, O.; Tizabi, Y. Antidepressant effects of resveratrol in an animal model of depression. Behav. Brain Res. 2014, 268, 1-7.

(13) Bencan, Z.; Sledge, D.; Levin, E. D. Buspirone, chlordiazepoxide and diazepam effects in a zebrafish model of anxiety. Pharmacol., Biochem. Behav. 2009, 94, 75-80.
(14) Stewart, A.; Wu, N.; Cachat, J.; Hart, P.; Gaikwad, S.; Wong, K.; Utterback, E.; Gilder, T.; Kyzar, E.; Newman, A.; et al. Pharmacological modulation of anxiety-like phenotypes in adult zebrafish behavioral models. Prog. Neuro-Psychopharmacol. Biol. Psychiatry 2011, 35, 1421-1431.

(15) Ibrahim, M.; Mussulini, B. H. M.; Moro, L.; de Assis, A. M.; Rosemberg, D. B.; de Oliveira, D. L.; Rocha, J. B. T.; Schwab, R. S.; Schneider, P. H.; Souza, D. O.; Rico, E. P. Anxiolytic effects of diphenyl diselenide on adult zebrafish in a novelty paradigm. Prog. Neuro-Psychopharmacol. Biol. Psychiatry 2014, 54, 187-194.

(16) Chakravarty, S.; Maitra, S.; Reddy, R. G.; Das, T.; Jhelum, P.; Kootar, S.; Rajan, W. D.; Samanta, A.; Samineni, R.; Pabbaraja, S.; et al. A novel natural product inspired scaffold with robust neurotrophic, neurogenic and neuroprotective action. Sci. Rep. 2015, 5, No. 14134

(17) Kumar, V. P.; Reddy, R. G.; Vo, D. D.; Chakravarty, S.; Chandrasekhar, S.; Gree, R. Synthesis and neurite growth evaluation of new analogues of honokiol, a neolignan with potent neurotrophic activity. Bioorg. Med. Chem. Lett. 2012, 22, 1439-1444.

(18) Shigemori, H.; Wakuri, S.; Yazawa, K.; Nakamura, T.; Sasaki, T.; Kobayashi, J. Fellutamides A and B, cytotoxic peptides from a marine fish-possessing fungus Penicillium fellutanum. Tetrahedron 1991, 47, 8529-8534.

(19) Lin, G.; Li, D.; Chidawanyika, T.; Nathan, C.; Li, H. Fellutamide B is a potent inhibitor of the Mycobacterium tuberculosis proteasome. Arch. Biochem. Biophys. 2010, 501, 214-220.

(20) Hines, J.; Groll, M.; Fahnestock, M.; Crews, C. M. Proteasome inhibition by fellutamide $\mathrm{B}$ induces nerve growth factor synthesis. Chem. Biol. 2008, 15, 501-512.

(21) Schneekloth, J. S., Jr.; Sanders, J. L.; Hines, J.; Crews, C. M. Neurotrophic peptide aldehydes: Solid phase synthesis of fellutamide B and a simplified analog. Bioorg. Med. Chem. Lett. 2006, 16, 38553858.

(22) Giltrap, A. M.; Cergol, K. M.; Pang, A.; Britton, W. J.; Payne, R. J. Total synthesis of fellutamide B and deoxy-fellutamides B, C, and D. Mar. Drugs 2013, 11, 2382-2397.

(23) Yadav, J. S.; Dachavaram, S. S.; Grée, R.; Das, S. Solution phase synthetic approach to fellutamide B. Tetrahedron Lett. 2015, 56, 3999-4001.

(24) Schneekloth, J. S.; Sanders, J. L.; Hines, J.; Crews, C. M. Neurotrophic peptide aldehydes: Solid phase synthesis of fellutamide B and a simplified analog. Bioorg. Med. Chem. Lett. 2006, 16, 38553858.

(25) Yadav, J. S.; Dachavaram, S. S.; Peddapuram, A.; Das, S. Convergent synthesis of panclicin-D via intramolecular SN2 displacement approach. Tetrahedron Lett. 2014, 55, 1952-1955.

(26) Sharma, A.; Gamre, S.; Chattopadhyay, S. An asymmetric synthesis of sulfobacin A. Tetrahedron Lett. 2007, 48, 3705-3707.

(27) Sharma, G. V.; Babu, B. S.; Ramakrishna, K. V.; Nagendar, P.; Kunwar, A. C.; Schramm, P.; Baldauf, C.; Hofmann, H. J. Synthesis and Structure of $\alpha / \delta$-Hybrid Peptides-Access to Novel Helix Patterns in Foldamers. Chem. - Eur. J. 2009, 15, 5552-5566.

(28) Sharma, G. V.; Babu, B. S.; Chatterjee, D.; Ramakrishna, K. V.; Kunwar, A. C.; Schramm, P.; Hofmann, H.-J. Theoretical and Experimental Studies on $\alpha / \varepsilon$-Hybrid Peptides: Design of a 14/12Helix from Peptides with Alternating (S)-C-Linked Carbo- $\varepsilon$-amino Acid [(S)- $\varepsilon$-Caa (x)] and 1-Ala. J. Org. Chem. 2009, 74, 6703-6713.

(29) Joëls, M.; Karst, H.; Krugers, H. J.; Lucassen, P. J. Chronic stress: implications for neuronal morphology, function and neurogenesis. Front. Neuroendocrinol. 2007, 28, 72-96.

(30) Yun, J.; Koike, H.; Ibi, D.; Toth, E.; Mizoguchi, H.; Nitta, A.; Yoneyama, M.; Ogita, K.; Yoneda, Y.; Nabeshima, T.; et al. Chronic restraint stress impairs neurogenesis and hippocampus-dependent fear memory in mice: possible involvement of a brain-specific transcription factor Npas4. J. Neurochem. 2010, 114, 1840-1851.

(31) Warner-Schmidt, J. L.; Duman, R. S. Hippocampal neurogenesis: opposing effects of stress and antidepressant treatment. Hippocampus 2006, 16, 239-249. 
(32) Westenbroek, C.; Den Boer, J. A.; Veenhuis, M.; Ter Horst, G. J. Chronic stress and social housing differentially affect neurogenesis in male and female rats. Brain Res. Bull. 2004, 64, 303-308.

(33) Joshi, P. C.; Samineni, R.; Bhattacharya, D.; Reddy, B. R.; Veeraval, L.; Das, T.; Maitra, S.; Wahul, A. B.; Karri, S.; Pabbaraja, S.; et al. A 2-oxa-spiro [5.4] decane scaffold displays neurotrophic, neurogenic and anti-neuroinflammatory activities with high potential for development as a versatile CNS therapeutic. Sci. Rep. 2017, 7, No. 1492.

(34) Hanson, N. D.; Owens, M. J.; Nemeroff, C. B. Depression, antidepressants, and neurogenesis: a critical reappraisal. Neuropsychopharmacology 2011, 36, 2589.

(35) Kronenberg, G.; Kirste, I.; Inta, D.; Chourbaji, S.; Heuser, I.; Endres, M.; Gass, P. Reduced hippocampal neurogenesis in the GR +/- genetic mouse model of depression. Eur. Arch. Psychiatry Clin. Neurosci. 2009, 259, 499-504.

(36) Hill, A. S.; Sahay, A.; Hen, R. Increasing adult hippocampal neurogenesis is sufficient to reduce anxiety and depression-like behaviors. Neuropsychopharmacology 2015, 40, 2368.

(37) Duman, R. S.; Monteggia, L. M. A neurotrophic model for stress-related mood disorders. Biol. Psychiatry 2006, 59, 1116-1127.

(38) Chakravarty, S.; Maitra, S.; Reddy, R. G.; Das, T.; Jhelum, P.; Kootar, S.; Rajan, W. D.; Samanta, A.; Samineni, R.; Pabbaraja, S.; et al. A novel natural product inspired scaffold with robust neurotrophic, neurogenic and neuroprotective action. Sci. Rep. 2015, 5, No. 14134.

(39) Chakravarty, S.; Reddy, B. R.; Sudhakar, S. R.; Saxena, S.; Das, T.; Meghah, V.; Swamy, C. V. B.; Kumar, A.; Idris, M. M. Chronic unpredictable stress (CUS)-induced anxiety and related mood disorders in a zebrafish model: altered brain proteome profile implicates mitochondrial dysfunction. PLoS One 2013, 8, No. e63302. (40) Egan, R. J.; Bergner, C. L.; Hart, P. C.; Cachat, J. M.; Canavello, P. R.; Elegante, M. F.; Elkhayat, S. I.; Bartels, B. K.; Tien, A. K.; Tien, D. H.; et al. Understanding behavioral and physiological phenotypes of stress and anxiety in zebrafish. Behav. Brain Res. 2009, 205, 38-44.

(41) Nguyen, N.; Lee, S. B.; Lee, Y. S.; Lee, K.-H.; Ahn, J.-Y. Neuroprotection by NGF and BDNF against neurotoxin-exerted apoptotic death in neural stem cells are mediated through Trk receptors, activating PI3-kinase and MAPK pathways. Neurochem. Res. 2009, 34, 942-951.

(42) von Bohlen und Halbach, O.; von Bohlen und Halbach, V. BDNF effects on dendritic spine morphology and hippocampal function. Cell Tissue Res. 2018, 1-13.

(43) Castrén, E.; Rantamäki, T. The role of BDNF and its receptors in depression and antidepressant drug action: reactivation of developmental plasticity. Dev. Neurobiol. 2010, 70, 289-297.

(44) Angelucci, F.; Brene, S.; Mathe, A. BDNF in schizophrenia, depression and corresponding animal models. Mol. Psychiatry 2005, 10,345 .

(45) Karege, F.; Perret, G.; Bondolfi, G.; Schwald, M.; Bertschy, G.; Aubry, J.-M. Decreased serum brain-derived neurotrophic factor levels in major depressed patients. Psychiatry Res. 2002, 109, 143-148.

(46) Réus, G. Z.; Stringari, R. B.; Ribeiro, K. F.; Ferraro, A. K.; Vitto, M. F.; Cesconetto, P.; Souza, C. T.; Quevedo, J. Ketamine plus imipramine treatment induces antidepressant-like behavior and increases CREB and BDNF protein levels and PKA and PKC phosphorylation in rat brain. Behav. Brain Res. 2011, 221, 166-171. (47) Garcia, L. S.; Comim, C. M.; Valvassori, S. S.; Réus, G. Z.; Barbosa, L. M.; Andreazza, A. C.; Stertz, L.; Fries, G. R.; Gavioli, E. C.; Kapczinski, F.; Quevedo, J. Acute administration of ketamine induces antidepressant-like effects in the forced swimming test and increases BDNF levels in the rat hippocampus. Prog. NeuroPsychopharmacol. Biol. Psychiatry 2008, 32, 140-144.

(48) Renthal, W.; Maze, I.; Krishnan, V.; Covington, H. E.; Xiao, G.; Kumar, A.; Russo, S. J.; Graham, A.; Tsankova, N.; Kippin, T. E.; et al. Histone deacetylase 5 epigenetically controls behavioral adaptations to chronic emotional stimuli. Neuron 2007, 56, 517-529.

(49) Tsankova, N. M.; Kumar, A.; Nestler, E. J. Histone modifications at gene promoter regions in rat hippocampus after acute and chronic electroconvulsive seizures. J. Neurosci. 2004, 24, $5603-5610$

(50) Tsankova, N.; Renthal, W.; Kumar, A.; Nestler, E. J. Epigenetic regulation in psychiatric disorders. Nat. Rev. Neurosci. 2007, 8, 355.

(51) Wang, Y.; Neumann, M.; Hansen, K.; Hong, S. M.; Kim, S.; Noble-Haeusslein, L. J.; Liu, J. Fluoxetine increases hippocampal neurogenesis and induces epigenetic factors but does not improve functional recovery after traumatic brain injury. J. Neurotrauma 2011, 28, 259-268.

(52) Ma, D. K.; Marchetto, M. C.; Guo, J. U.; Ming, G.-1.; Gage, F. $\mathrm{H}$.; Song, H. Epigenetic choreographers of neurogenesis in the adult mammalian brain. Nat. Neurosci. 2010, 13, 1338.

(53) Henn, F. A.; Vollmayr, B. Neurogenesis and depression: etiology or epiphenomenon? Biol. Psychiatry 2004, 56, 146-150.

(54) Kubera, M.; Obuchowicz, E.; Goehler, L.; Brzeszcz, J.; Maes, M. In animal models, psychosocial stress-induced (neuro) inflammation, apoptosis and reduced neurogenesis are associated to the onset of depression. Prog. Neuro-Psychopharmacol. Biol. Psychiatry 2011, 35, 744-759.

(55) Jacobs, B. L. Adult brain neurogenesis and depression. Brain, Behav., Immun. 2002, 16, 602-609.

(56) Martinowich, K.; Manji, H.; Lu, B. New insights into BDNF function in depression and anxiety. Nat. Neurosci. 2007, 10, 1089.

(57) Xu, Y.; Ku, B.; Cui, L.; Li, X.; Barish, P. A.; Foster, T. C.; Ogle, W. O. Curcumin reverses impaired hippocampal neurogenesis and increases serotonin receptor 1A mRNA and brain-derived neurotrophic factor expression in chronically stressed rats. Brain Res. 2007, $1162,9-18$.

(58) Jiang, W.; Zhang, Y.; Xiao, L.; Van Cleemput, J.; Ji, S.-P.; Bai, G.; Zhang, X. Cannabinoids promote embryonic and adult hippocampus neurogenesis and produce anxiolytic-and antidepressant-like effects. J. Clin. Invest. 2005, 115, 3104.

(59) Piato, Â. L.; Capiotti, K. M.; Tamborski, A. R.; Oses, J. P.; Barcellos, L. J. G.; Bogo, M. R.; Lara, D. R.; Vianna, M. R.; Bonan, C. D. Unpredictable chronic stress model in zebrafish (Danio rerio): behavioral and physiological responses. Prog. Neuro-Psychopharmacol. Biol. Psychiatry 2011, 35, 561-567.

(60) Stewart, A.; Gaikwad, S.; Kyzar, E.; Green, J.; Roth, A.; Kalueff, A. V. Modeling anxiety using adult zebrafish: a conceptual review. Neuropharmacology 2012, 62, 135-143.

(61) Marcon, M.; Herrmann, A. P.; Mocelin, R.; Rambo, C. L.; Koakoski, G.; Abreu, M. S.; Conterato, G. M.; Kist, L. W.; Bogo, M. R.; Zanatta, L.; et al. Prevention of unpredictable chronic stressrelated phenomena in zebrafish exposed to bromazepam, fluoxetine and nortriptyline. Psychopharmacology 2016, 233, 3815-3824.

(62) Reddy, R. G.; Veeraval, L.; Maitra, S.; Chollet-Krugler, M.; Tomasi, S.; Lohézic-Le Dévéhat, F.; Boustie, J.; Chakravarty, S. Lichen-derived compounds show potential for central nervous system therapeutics. Phytomedicine 2016, 23, 1527-1534.

(63) Karisetty, B. C.; Joshi, P. C.; Kumar, A.; Chakravarty, S. Sex differences in the effect of chronic mild stress on mouse prefrontal cortical BDNF levels: A role of major ovarian hormones. Neuroscience 2017, 356, 89-101.

(64) Chakravarty, S.; Pathak, S. S.; Maitra, S.; Khandelwal, N.; Chandra, K. B.; Kumar, A. Epigenetic Regulatory Mechanisms in Stress-Induced Behavior. International Review of Neurobiology; Elsevier, 2014; pp 117-154. 